\title{
Methodological guide for the assembly of a pumping system through solar panels
}

\author{
Elquin B. Mejía ${ }^{\# 1}$, Esmerlis Camargo ${ }^{* 2}$, Carlos E. Robles ${ }^{* 3}$

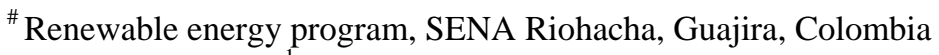 \\ ${ }^{1}$ emejiasu@misena.edu.co \\ * Industries and Alternative Energy Center, SENA Riohacha, Guajira, Colombia \\ 2 ecamargot@sena.edu.co \\ 3 croblesp@sena.edu.co
}

\begin{abstract}
In the present work a methodological guide is presented to the assembly of a water pumping system by means of solar panels. As a case study, the guide was implemented by the apprentices of the Technical Program in Maintenance and Installation of Photovoltaic Solar Systems, belonging to the Industrial Center and alternative energies of the National Service of Learning - SENA Regional Guajira, Colombia. The methodology applied was experimental, descriptive, field and cross-sectional. The results allowed us to obtain a pumping system capable of transporting 28 liters of water daily from a well in a tank, in an area with an irradiation potential between 5.5 and $6.0 \mathrm{KWh} / \mathrm{m}^{2}$. Among the conclusions found, the feasibility of the system as a means for supplying water in communities and supplying the demand is highlighted. Likewise, the project aims to encourage the use of solutions with photovoltaic solar energy.
\end{abstract}

Keyword - Renewable energy, solar energy, water supply, rural space, hard to reach areas.

\section{INTRODUCTION}

At present, problems such as access to water and desertification of land have affected different regions and populations of the world [1] [2], which means that means such as pumping irrigation systems are used to confront these problems. However, in a conventional manner, these systems have been designed with power sources based on electricity or diesel, a factor that presents problems such as deficits and high costs [3].

In search of solving the previous difficulty, renewable energy sources have been used, which by previous investigations have been classified into five large groups, such as: solar photovoltaic water pumping system (SPWPS), solar thermal water pumping system (STWPS), wind energy water pumping system (WEWPS), biomass water pumping system (BWPS) and hybrid renewable energy water pumping systems (HREWPS) [4].

Among the most used pumping systems, there are photovoltaic implementations like the one observed in [5], in which a dynamic modeling tool was developed for the design of a photovoltaic water pumping system, which combines models of water demand, photovoltaic solar energy and pumping system. Similarly, in [6] a photovoltaic system was proposed for irrigation of independent direct pumping and optimal for the deficient irrigation of olive orchards. Finally, in [2] they proposed an optimization procedure that considers the availability of groundwater resources, the effect of water supply on crop yields and the investment cost of the photovoltaic water pumping system together with the income from the sale of crops.

For the assembly of photovoltaic pumping systems, different types of pumps must be taken into account: submersible, such as those used in [7] to irrigate fields of livestock and wildlife affected by droughts, and in [8] in order to implement in Oliveira de Frades, Portugal, a lawn irrigation system in a company; and surface, as the work done in [9], focused on reviewing the design of SPWPSs at minimum cost for Palestine.

There are documents that serve as support for the installation of SPWPS, for example [10], in which an SPWPS installation manual was made in Potreritos, Nicaragua, to allow future growth in system performance and water production; or the guide [11] for the installation of SPWPS in New York by farmers and landowners. However, manuals and guides like the previous ones do not have a focus on the teaching and training of apprentices in educational institutions, but rather they target an independent public.

Therefore, a methodological guide is proposed to the assembly of a pumping system through solar panels, with the purpose of supporting and promoting the training of apprentices in the renewable energy training programs of the Industrial Center and alternative energies of the National Apprenticeship Service - SENA Regional Guajira, Colombia. 


\section{Methodology}

Methodologically, it is an experimental, descriptive, field and cross-sectional research, oriented to be done by apprentices of the renewable energy training programs of the Industrial Center and alternative energies of the National Apprenticeship Service - SENA, Regional Guajira. Experimental, because they are intended to take action before the study situation and observe the consequences of those actions [12]; descriptive when detailing the situation presented in the teaching to apprentices of mentioned training program [13]; of field, to observe the facts in their natural context; and cross-sectional because the study is done at a specific time [12].

\section{A. Scheme raised}

Based on the experience of the teachers of the training program under study, the stages in the assembly of a photovoltaic pumping system could be defined (Figure 1).

B.

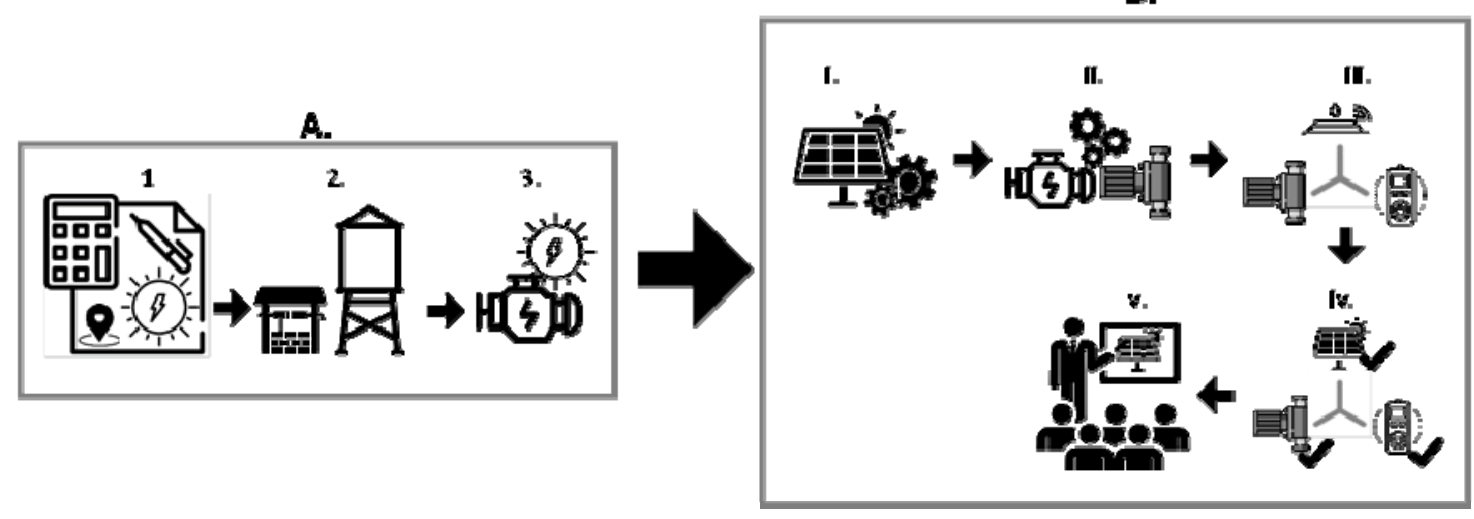

Fig. 1. A sample line graph using colors which contrast well both on screen and on a black-and-white hardcopy

A. Design of the SPWPS

1. Determination of energy potential in solar radiation at the geographical point where the installation of the system is needed

2. Determination of the quantity of water required daily, depth of extraction, distance and height of discharge

3. Define other sources of energy for contingency

B. Installation of the SPWPS

i. Installation of solar panels

1. Location, Assembly and foundation of the support structure for solar panels

2. Installation of solar panels

3. Connection of the panels and wiring to the controller applying the RETIE standards

4. Driver installation

\section{ii. Installation of the pump}

To carry out this step, the source of water is verified, then the motor and pump are assembled, the wiring is connected with epoxy tubular insulating and heat shrinkable connectors, in order to finally tie the lifeline to the electric pump.

\section{iii. Installation of sensors}

The pump is inserted into the well, respecting the safety regulations and assembling the hydraulic pipe, then the sensors are installed, the pump cable and sensors are connected to the controller, and then the grounding is installed.

iv. Verification of the connection and operation of the SPWPS system

Mechanical, electrical connections are checked and the operation of the system is verified.

v. Delivery of the system and training for its use

The operation and maintenance manual is delivered to the owner and operator of the system; times are set for a training session to the system operator. 


\section{III.RESULTS}

The installation of an SPWPS must be carried out by qualified personnel so that all the activities carried out in the field comply with the standards established in the electrical technical regulation, thus avoiding possible failures that may arise in the elements that make up the system and the reliability and durability of the system is maximized. The planning of the execution of the project is fundamental, as well as the willing logistics, the technical installer must ensure that all the materials and tools are available.

The following case study was used in a SENA headquarters - Guajira Regional, Colombia, along with apprentices and teachers, in order to apply the guide step by step.

The type of pumping selected was indirect pumping, because water was extracted from a well and stored in a tank and then distributed.

In the study of photovoltaic solar installations, the single-line diagrams are used to illustrate the different components that are part of a renewable energy installation, in the case of photovoltaic solar, for this reason object analysis is done to the solar panels, to the regulator, to the batteries, to the inverter, to the wiring and to the protections of individual way, to then proceed to the interpretation of plane.

To carry out this process, it is necessary to list the technical specifications of the preparation of the single-line diagram. In the present wedding the design was chosen in the Franklin Electric application (Figure 2), which shows the Solar SubDrive that has been designed to be part of a system, composed of:

- Motor and Solar Pumps

- Solar Subdrive Controller

- Solar set

- Flow switch (with sensor cable)

- Upper / lower level control switch

- AC generator

- 2-pole DC rated power disconnect

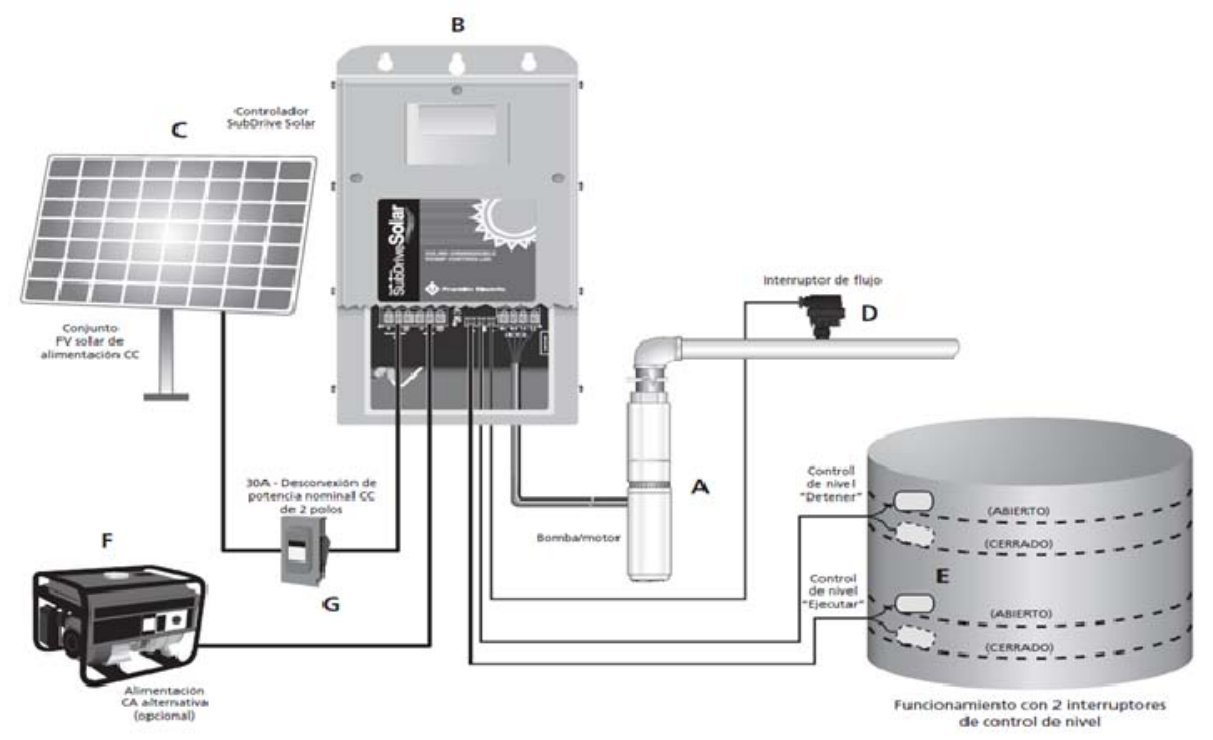

Fig. 2: Solar SubDrive system

\section{A. Design of the SPWPS}

1. The entire document should be in Times New Roman or Times font. Type 3 fonts must not be used. Other font types may be used if needed for special purposes.

Through the Interactive Atlas of the IDEAM [14] (Figure 3), it was determined that the solar energy potential for the Riohacha area, where the SENA headquarters are located, is approximately between 5.5 and $6.0 \mathrm{kWh} /$ $\mathrm{m}^{2}$. 


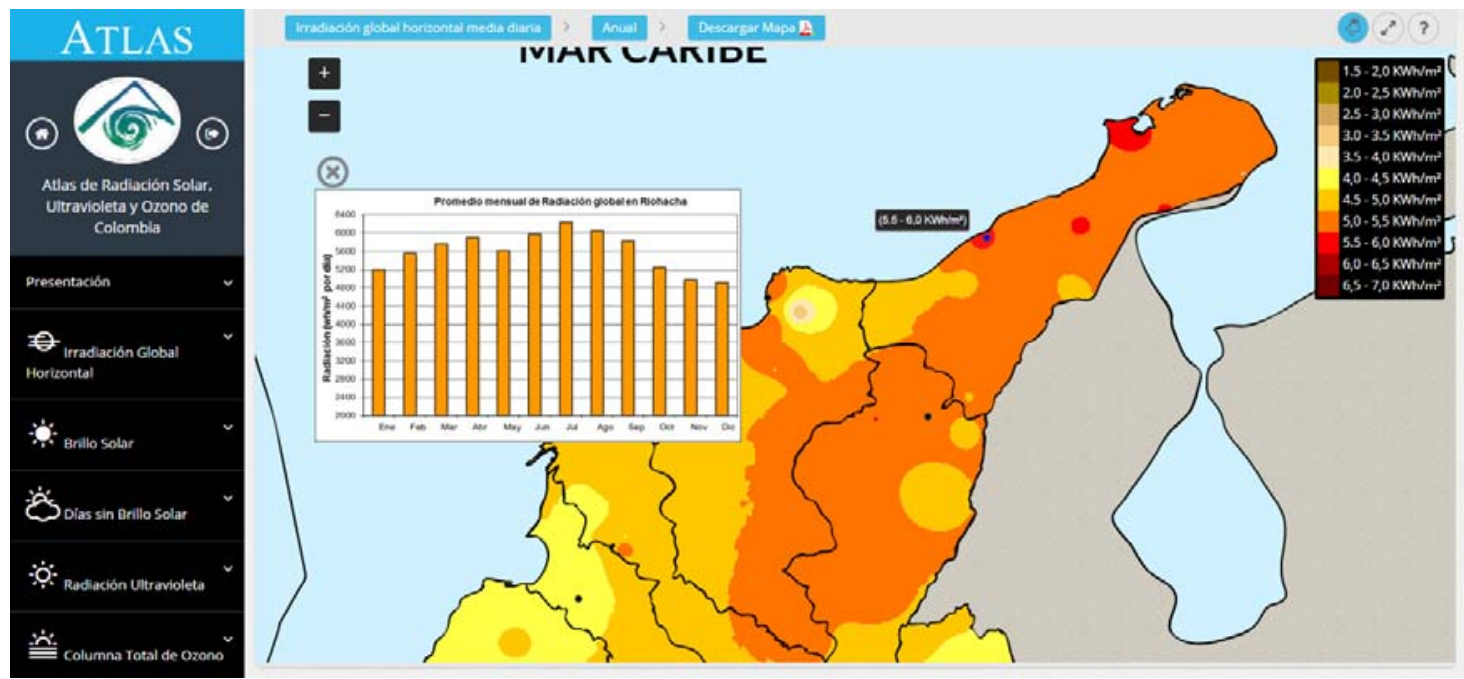

Fig. 3: Atlas of solar radiation, IDEAM

2. Determination of the quantity of water required daily, depth of extraction, distance and height of discharge

In the present case, it was determined that the amount of water to be pumped out of 28 cubic meters per day.

3. Define other sources of energy for contingency

The conventional electric fluid, which provides 220 volts of alternating current, was chosen as a contingency source.

\section{B. Installation of the SPWPS}

vi. Installation of solar panels

1. Location, Assembly and foundation of the support structure for solar panels

A structure with support on an aluminum floor was used for 11 panels of 270W (Figure 4), which was assembled by the apprentices of the Technical Program in Maintenance and Installation of Photovoltaic Solar Systems.

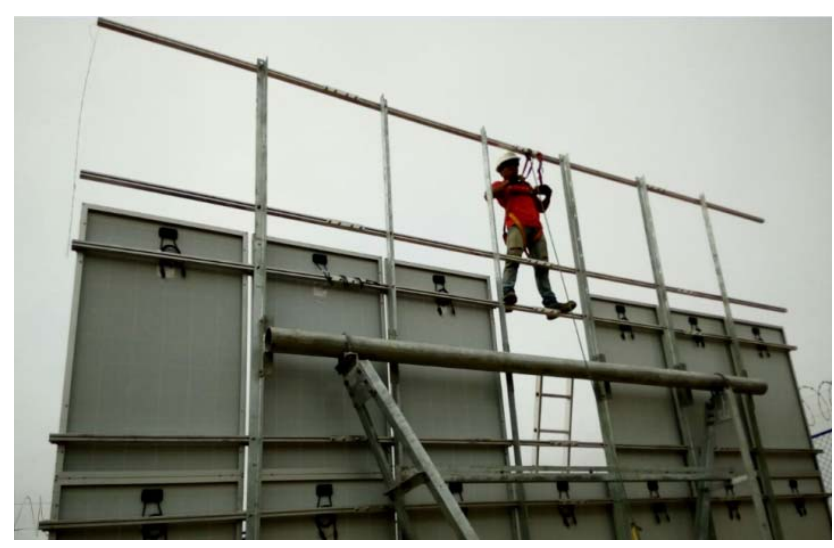

Fig. 4: Structure assembly

2. Installation of solar panels

Eight PANEL POLI 270W solar panels were installed. It was done by the trainees with supervision and help from the teachers and guides (Figure 5). 


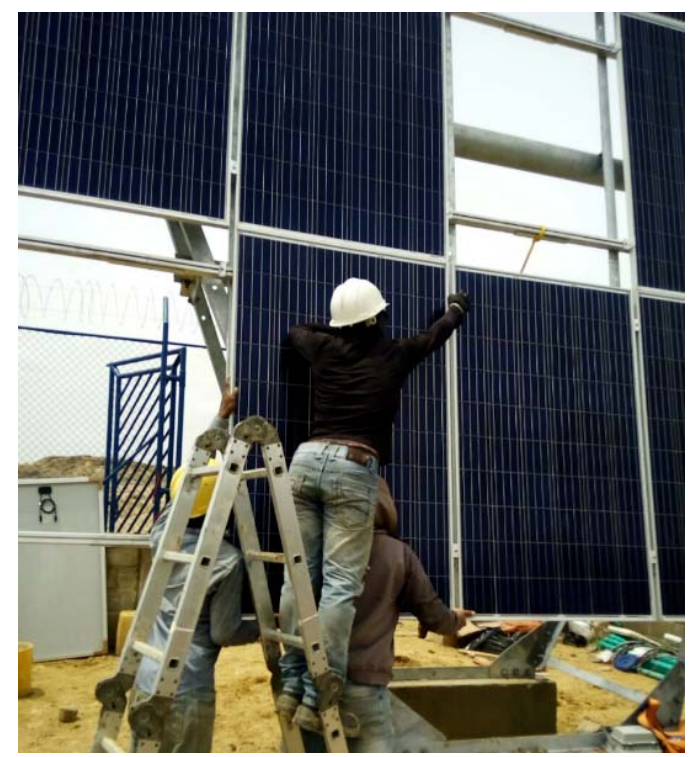

Fig. 5: Installation of solar panels

3. Connection of the panels and wiring to the controller applying the RETIE standards

Solar cable XL 8mm SK10TC-5 SOLAR KABEL (30 units) was used as a means of connection between panels and controller.

\section{Driver installation}

The controller was installed on a solid support structure as was a wall, which had characteristics to hold the unit taking into account the weight.

The electrical components inside the Solar SubDrive are cooled by air. Therefore, they were left at least 45.7 cm (18 in) above and below to allow air flow and adequate cooling.

The SubDrive Solar controller was installed with the wiring end facing down, as instructed. In addition, to ensure optimum performance, it was installed in an installation without direct sunlight, humidity and extreme temperatures. Exposure of the controller to direct sunlight or high ambient temperatures will cause performance to be reduced due to temperature reduction protection. For optimal performance, the shadow of the controller is maximized.

\section{i. Installation of the pump}

When carrying out this step, the water source was verified with a probe to confirm that the static water level coincided with the design information that the well builder delivered. Then the motor and the pump were assembled, for which the precaution was taken to adjust the screws with the torque indicated by the manufacturer and that the cables that come out of the motor will be aligned with the cable gutter of the pump (Figure 6). 

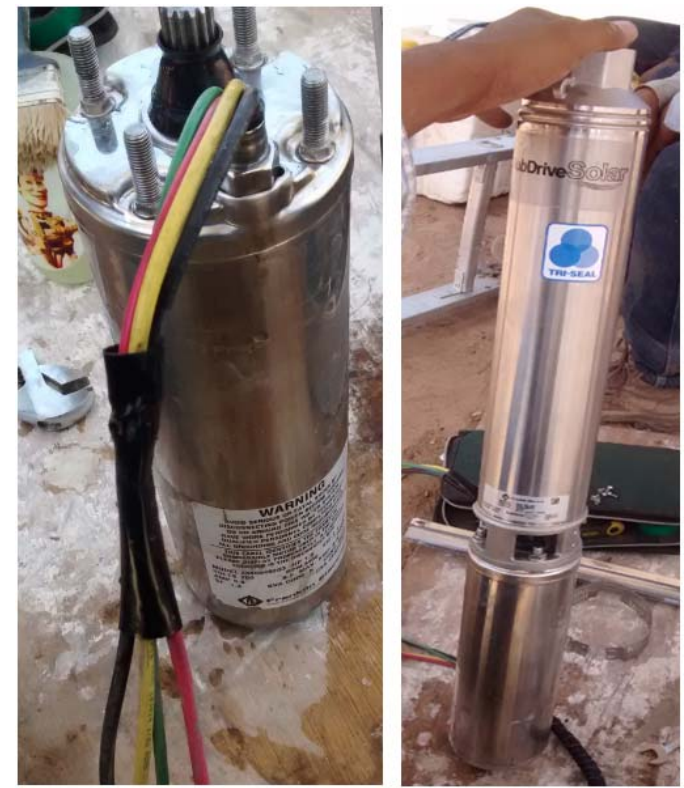

Fig. 6: Engine and pump assembly

Subsequently, the wiring was connected with epoxy tubular insulating and heat shrinkable connectors (Figure 7), to provide protection against corrosion that could occur in the joint and that would affect the flow of current in the connection to the motor, in addition, that would protect Isolated way the conductor of any mechanical contact that will cause current leakage or short circuit. Finally, the lifeline was attached to the electric pump (Figure 8).

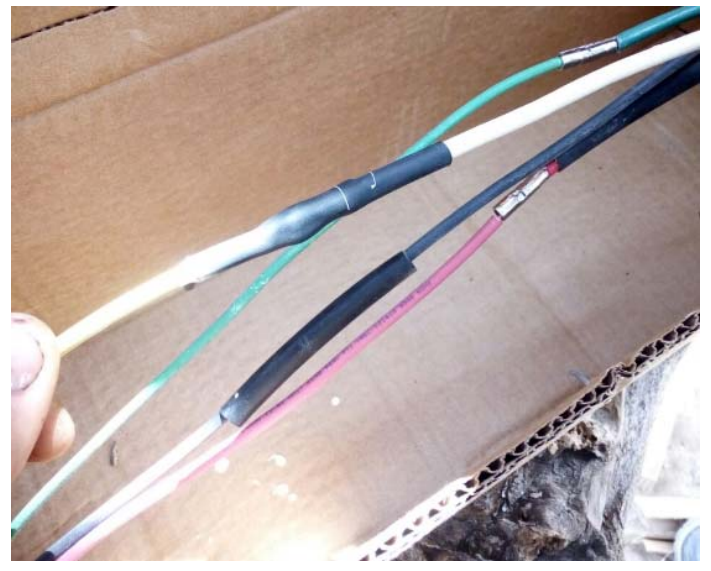

Fig. 7: Wiring splice

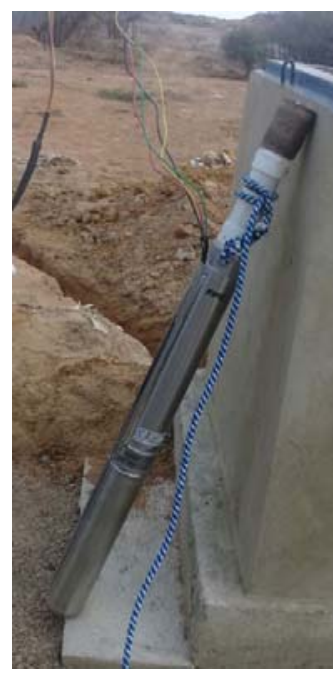

Fig. 8: Lifeline mooring 


\section{ii. Installation of sensors}

The pump was introduced into the well (Figure 9), respecting the safety standards and assembling the hydraulic pipe, then the sensors were installed (Figure 10), the pump and sensor cables were connected to the controller, and then the grounding.

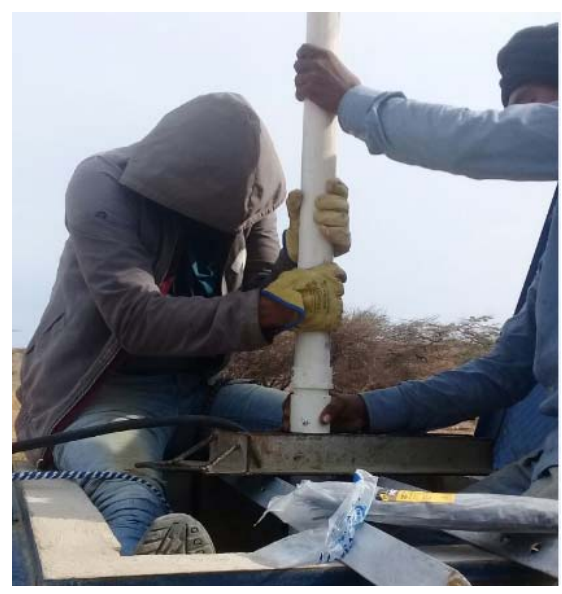

Fig. 9: Process of introduction of pump inside well

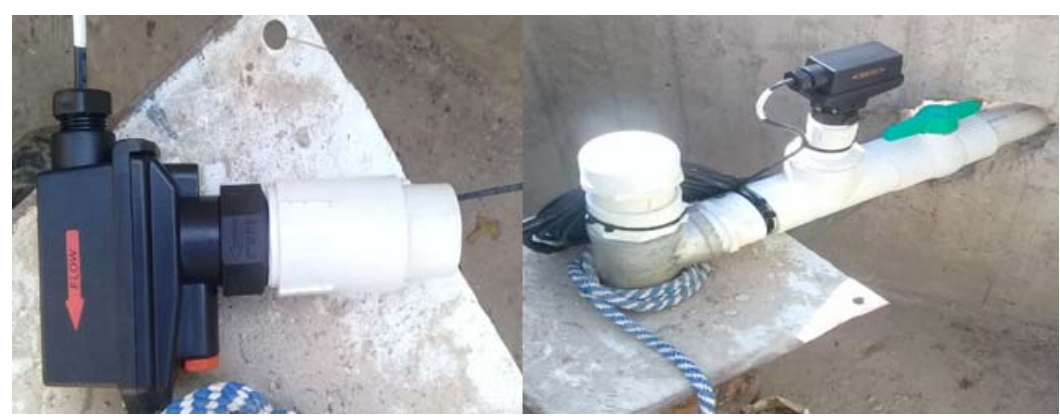

Fig. 10: Installation of sensors

iii. Verification of the connection and operation of the SPWPS system

Mechanical, electrical connections are checked and the operation of the system is verified.

iv. Delivery of the system and training for its use

The operation and maintenance manual was delivered to the owner and operator of the system, and times were set for a training session for the system operator.

Applying the previous guide, it was possible to obtain a functional SPWPS and apt to be replicated. The apprentices of the Technical Program in Maintenance and Installation of Solar Photovoltaic Systems, were able to verify that the system complied with the basic requirements for its operation and verified that it fully fulfilled the function of pumping water.

Projects such as the one carried out in [10], allowed corroborating in a bibliographic way the need for an updated guide to implement SPWPS. In addition, along with projects such as [11], points of comparison were obtained between the sequence shown in the scheme of Figure 1 and that possessed by the cited documents.

\section{CONCLUSION}

After what was done, it was concluded that, according to the stated objectives, the use of natural resources for energy production, in this case through a photovoltaic solar system, is a feasible alternative for water supply in communities and meet the demand.

Likewise, to maintain a culture of reasonable use of renewable energies, it is required that all involved participate in the following strategies: experiences and testimonies of apprentices and members of the beneficiary community; spaces for meeting and disseminating projects such as meetings of researchers and science and technology fairs; sensitize and train the beneficiary communities for the maintenance and use of the technologies delivered to reduce deterioration through use.

With the implementation of this project, it is intended to encourage the use of solutions with photovoltaic solar energy, in this way it will be possible to take advantage of the regulation of the law of renewable energies 1715. On the other hand, it is pertinent to conclude that water pumping applications are highly necessary in the communities of the department in ZNI (non-interconnected areas), which makes this research a model to be 
replicated by users who require it through our trained trainees, this is reflected in the reduction of costs in energy consumption and finally in the contribution to the protection of the planet.

\section{REFERENCES}

[1] P. Caton, "Design of rural photovoltaic water pumping systems and the potential of manual array tracking for a West-African village," Solar Energy, vol. 103, pp. 288-302, 2014.

[2] P.E. Campana, H. Li, J. Zhang, R. Zhang, J. Liu and J. Yan, "Economic optimization of photovoltaic water pumping systems for irrigation,” Energy Conversion and Management, vol. 95, pp. 32-41, 2015.

[3] S.S. Chandel, M. Nagaraju and R. Chandel, "Review of solar photovoltaic water pumping system technology for irrigation and community drinking water supplies,” Renewable and Sustainable Energy Reviews, vol.49, pp. 1084-1099, 2015.

[4] C. Gopal, M. Mohanraj, P. Chandramohan and P. Chandrasekar, "Renewable energy source water pumping systems-A literature review," Renewable and Sustainable Energy Reviews, vol. 25, pp. 351-370, 2013.

[5] P.E. Campana, H. Li and J. Yan, "Dynamic modelling of a PV pumping system with special consideration on water demand," Applied Energy, vol. 112, pp. 635-645, 2013.

[6] R. López-Luque, J. Reca and J. Martínez, "Optimal design of a standalone direct pumping photovoltaic system for deficit irrigation of olive orchards,” Applied Energy, vol. 149, pp. 13-23, 2015.

[7] K. Meah, S. Fletcher and S. Ula, "Solar photovoltaic water pumping for remote locations," Renewable and Sustainable Energy Reviews, vol. 12, issue 2, pp. 472-487, 2008.

[8] M. I. Cardoso, "Photovoltaic powered water pumping systems: design and optimization of an irrigation system," M. Eng. thesis, Universidade de Lisboa, Lisboa, Portugal, 2014.

[9] T. Khatib, "Design of photovoltaic water pumping systems at minimum cost for Palestine: A review," Journal of Applied Sciences, vol. 10, issue 22, pp. 2773-2784, 2010.

[10] Available: http://web.pdx.edu/ rueterj/courses/ESM342-solar/Installation\%20in\%20Potreritos-FINAL.pdf

[11] C. W. Sinton, R. Butler and R. Winnett, Guide to Solar-Powered Water Pumping System in New York State, NewYork, USA: Nyserda, 2017.

[12] E. Babbie, The basics of social research, 5th ed. California, USA: Cengage learning, 2011.

[13] R. Kumar, Research Methodology, a step-by-step guide for beginners, 3rd ed. London, England: SAGE, 2011.

[14] IDEAM, Atlas Interactivo - Radiacion IDEAM, Available: http://atlas.ideam.gov.co/visorAtlasRadiacion.html

\section{AUTHOR PROFILE}

Elquin B. Mejía works as full-time professor at the SENA (Colombia). Mr. Mejía completed his postgraduate study from North University (Colombia). Mr. Mejía completed his undergraduate in Electronic Engineer and telecommunications at the El Bosque University.

Esmerlis Camargo works as Research leader SENNOVA at the SENA (Colombia). Mrs. Camargo completed his PhD. from Rafael Belloso Chacín University (Colombia). Mrs. Camargo completed his undergraduate in Industrial Engineering at the University of La Guajira.

Carlos E. Robles works as subdirector of the Industries and Alternative Energy Center at the SENA (Colombia). Mr. Robles completed his magister from Externado University of Colombia (Colombia). Mr. Robles completed his undergraduate in Industrial Engineering at the University of La Guajira. 